Lep. Rev. (1968) 39, 1, :31-:36

\title{
Acute Epididymo-Orchitis in Lepromatous Leprosy
}

\author{
C. T. TILAK, M.B.B.s. (EX. I.M.s.) \\ 43/158 Dr. Tilak Street, Narasingaraopet, Kurnoo!, Andhra Pradesh, India \\ Former Assistant Director of Medical. Services (Leprosy Control), Hyderahad, Andhra Pradesh, India)
}

\section{INTRODUCTION}

Testicular involvement is a feature of leprosy, either frankly lepromatous, or at the lepromatous end of the dimorphous disease spectrum, Davey and Schenk (1964). On the other hand, lesions in testes in non-lepromatous patients seem to be extremely rare and are not well documented in literature, Job and Macaden (1963). V. R. Khanolkar (1964) has observed 'that the testes and their adnexa are preferentially affected in a large proportion of men suffering from lepromatous leprosy. The involvement of the testes and some of the larger nerve trunks needs special mention owing to our ignorance of the causes which determine the selectivity of the male gonad'. He further suggests the intervention of a generalised systemic process rather than that of a process localised to any individual tissue. Hanks and Backerman (1950), in their work on experimental transmission in rats, found the testes to be the most favourable site for multiplication of M. lepraemurium.

The study of testicular biopsies has been scarce 'as the patients are often reluctant to permit biopsy of skin lesions and not infrequently refuse, and where testicle biopsy is unthinkable'.-Editorial, Int. J. Lepr., H. W. Wade (1963). The editorial further continues 'since the testes are especially favourable to the location of bacillus one would expect that some degree of orchitis, observable clinically, would occur in at least an occasional case. Apparently, however, that condition has never been observed'.

The special tissue predilection of the testes as target organs for the lodgement of $M$. leprae in reactional states in lepromatous leprosy is well established and has been the subject of concentrated study by leprologists. Whether the epididymis, which forms a major component of the adnexae of the testes and seminal tract, participates in any leprous processes has not been sufficiently recognised, emphasised and documented except by A. L. Furniss (1956), who observed 'that the epididymis was always much less affected than the testis'. This clinical failure of the entity may be attributed to either paucity of clinical material, restricted opportunities, shyness and reluctance on the part of patients to expose their genitals or due to the specialised nature of studies by leprologists and pathologists, not surgically orientated.

Be that as it may, the epididymis does become involved together with the testes in reactional states in lepromatous leprosy. Its anatomical proximity, identical vascular supply and peculiar functions lend support to this view. The epididymis is $(a)$ passive and conductive (the spermatozoa pass through this structure on to the ductus deferens); $(b)$ active and secretory (the secretions of the epididymis form a large part of seminal fluid); and (c) finally functions as an excretory organ (excreting organisms from the blood with or without obvious local lesions), R. H. O. B. Robinson (1950).

Other possible etiological factors affecting the testes in leprosy may be cited here:-

(a) Trauma, Rogers and Muir (1952).

(b) Low temperature conducive to growth of $M$. leprae, Grabstald and Swan (1952).

(c) Attraction of bacillus to the surface of the superficial structures in contradistinction to the ovary which is deeply located in the abdominal cavity. 
(d) Spermatocyte reaction, Long (1925) revived by Feldman et al. (1961) proving that the testis is specially hypersensitised and receptive to the infecting agent.

(e) General adaptation syndrome of Hans Selye involving the defensive mechanism of the body during lepra reaction, E. Muir (1962).

This author controverts the editorial observations of Dr. Wade as acute epididymoorchitis does occur occasionally in severe reactional states in advanced lepromatous leprosy, and is observable clinically and, what is more, the patients themselves draw attention to the painful scrotal swellings which are always bilateral.

\section{MATERIAL AND METHODS}

Four patients with acute epididymo-orchitis in reactional states in advanced lepromatous leprosy have been studied. Their ages varied between 25-40 years. All were married. These patients were almost constantly suffering from reactions for a period varying between 5-15 years. They were under anti-leprosy treatment, off and on.

Their main complaint was severe testicular pain resistant to penicillin and sulfa therapy. General constitutional disturbances were evident. Skin smears were highly positive for M. leprae, with globi formation. V.D.R.L. test was negative in all patients. Rectal examination of prostate and seminal vesicles proved negative. External urethral meatus and lips were dry and healthy. There was no history of exposure or mucopurulent or sanious discharge per urethram Three of the patients were frankly impotent whilst the fourth had a semblance of libido.

Secondary sexual characteristics were noted in respect of distribution of hair-pubic, axillary and facial, which were sparse and feminine. Marked unilateral gynaecomastia was present in 3 patients and bilateral infiltration of the nipples in the fourth. Cervical lymphadenopathy was marked in one patient.

Low orchidectomies were performed on 2 patients, the third was submitted to biopsy and the fourth treated conservatively. Persuasion, coaxing, intense testicular pain, failure of standard treatment for gonococcal orchitis and a feeling of hopelessness have facilitated surgical intervention for the purpose of these studies.

The specimens were sent to 3 different pathologists of standing for histopathological studies. Clinical photography was possible in one patient only, Patient 4, as also photomicrography in another, Patient 3. The pathologists' reports are shown under the respective reports of patients.

Treatment consisted of oral chloromycetin $250 \mathrm{mg}$. six-hourly for 7 days, $500 \mathrm{mg}$. Vit. C daily, $100 \mathrm{mg}$. Pethidine I.M. and I.V. Decadron for the first 3 days followed by oral steroids for 3 weeks. All sulfones were withheld for 6 weeks. The patients were treated as emergencies. Postoperative follow-up and wound healing was uneventful. Complete subsidence of lepra reaction and diminution of scrotal swelling with disappearance of testicular pain were evident under steroid and higher antibiotic therapy.

\section{REPORTS OF PATIENTS}

Patient 1-G.L.S.C. 44/64, Laxmanna-Hindu-age 30 years. Illiterate, labourer, married, no children. History of leprosy-12 years-gives no history of exposure to venereal diseases. Duration of present attack of lepra reaction -3 weeks.

Chief complaint: Painful, tender, increasing bilateral scrotal swelling, rendering walking difficult and awkward. Duration about 10 days.

Clinical findings: Diffuse lepromatosis of nodular type with laryngeal changes, nasal deformity, oedematous extremities and bony resorptive changes of phalanges-Peripheral nerves thickened. Unilateral gynaecomastia present-left sicle.

Scrotal skin tense and shiny-not adherent-no sinus-testes swollen and excruciatingly tenderfeel hard-Epididymis on both sides markedly enlarged, hard and acutely tender-External urethral meatus healthy and dry with no discharge-Cord structures normal-Inguinal group of glands normal. Investigation: (a) Multiple skin clip smears were strongly positive for $M$. leprae, with globi formation; (b) V.D.R.L. test negative; (c) Rectal examination of prostate and seminal vesicles-not significant. Testis with cord and coverings was removed and sent to the Pathologist, Kurnool Medical College, Kurnool. Individual smears from these structures were positive for A.F.B.

Macroscopic findings: The testis and epididymis cut with grating sensation-cut surface greyish white in colour-firm and hard in consistency-a small hydrocele of tunica vaginalis present-normal seminiferous tubules could not be picked up with forceps - no beading of ductus deferens - other cord structures normal. 
Histopathological Report by Dr. C. Rajaram Mohana Reddy, M.D., Professor of Pathology, Department of Pathology, Kurnool Medical College, Kurnool. Register No. 607/64 dated 21.3.1964. Nature of specimen-Testis with cord and coverings. Report: Seminiferous tubules are hyalinized-No germinal cells or supporting cells nor Leydig's cells-Basement membrane of the tubules are thickened and hyalinized-chronic inflammatory tissue presentA.F.B. positive.

Patient 2-G.L.S.C. No. 201/63. P.K. Age 33 years. Muslim, vagrant, married, no children. History of leprosy about 15 years-Unilateral gynaecomastiaright side.

Diagnosis: Advanced lepromatous leprosy with acute epididymo-orchitis.

Histopathological Report by Dr. D. J. Reddy, M.D., Director, Upgraded Institute of Pathology, Andhra Medical College, Visakhapatnam, Andhra Pradesh. Biopsy No. 2474 A-F/63 dated 22.6.1963. Nature of specimen-Testis and adnexa-Lepromatous biopsy. Report: Scrotal skin-evidence of atrophy of the skin with total loss of adnexa. Dartos muscle, still preserved in areas. There is dense granulation tissue consisting of large foamy cells. A.F.B. $5 \%$ positive. A lymph node shows follicular hyperplasia, thickening of capsule subcapsular space and sinuses are filled with foam cells-A.F.B. $5 \%$ positive. Ductus

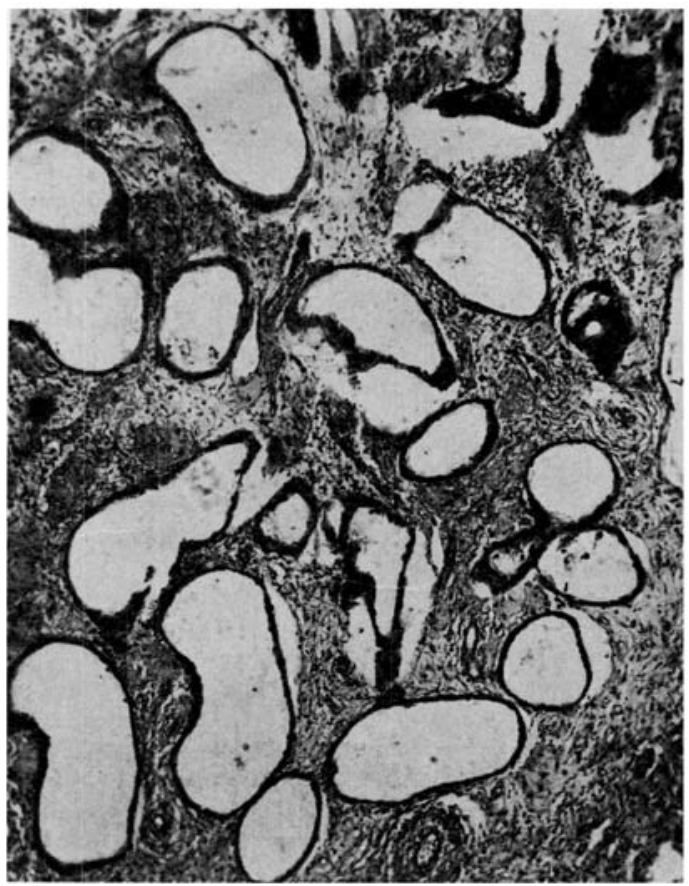

FIG. 1

Photo micrograph of testis in Leprosy. G.L.S.C. 201/63. H \& E $\times 80$.

Illustrates atrophic tubules of testis with fibrosis inflamatory cell reaction of interstitium and absence of spermatogenic activity.

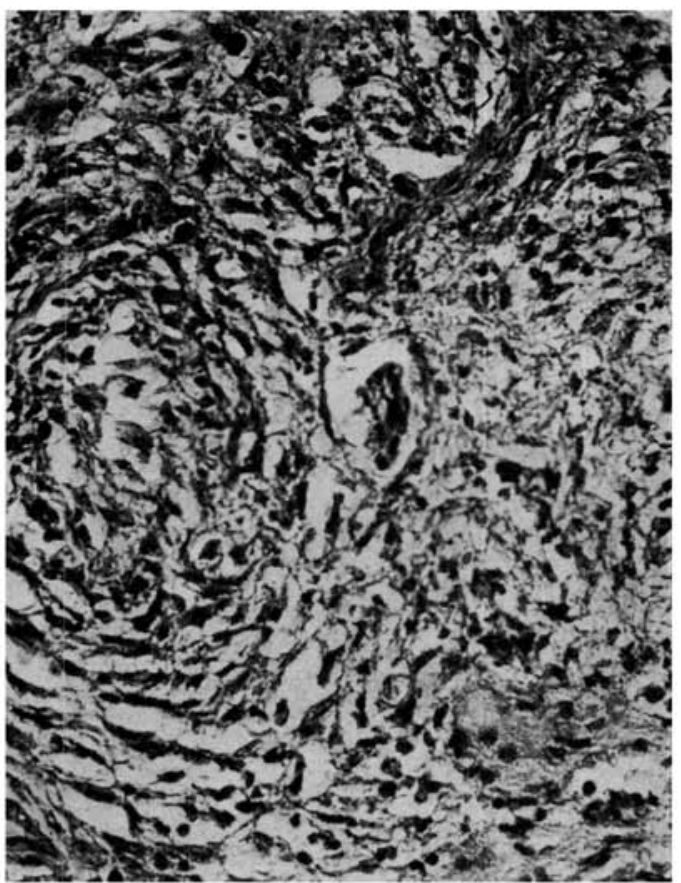

FIG. 2

G.L.S.C. $201 / 63$. H \& E $\times 168$

Testis in leprosy with round cell infiltration, A.F.B. and hyalinized tubules.

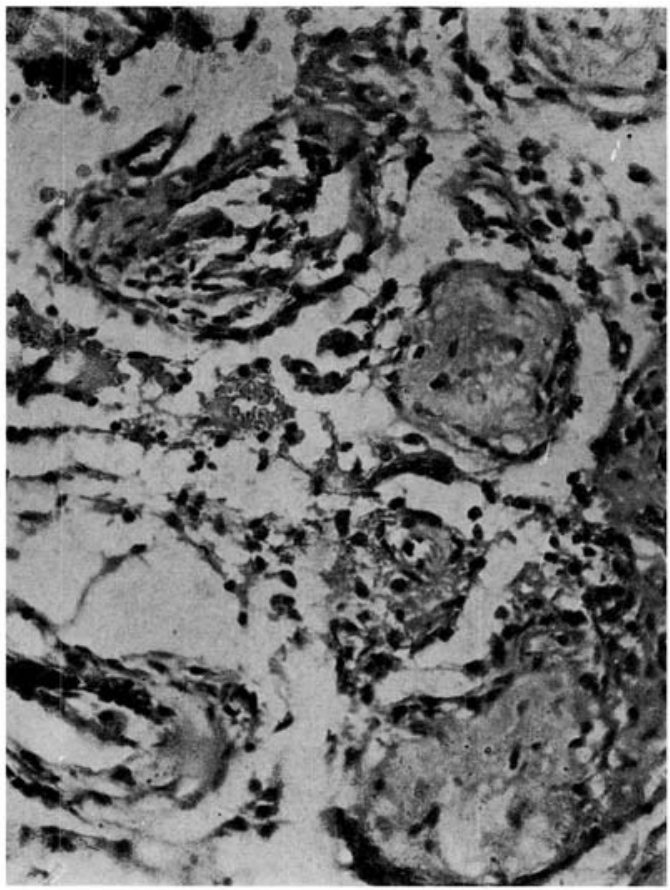

Fici. 3

G.L.S.C. $201 / 63$. H \& E $\times 168$

Testis in leprosy-granulomatous infiltration of stroma with A.F.B 


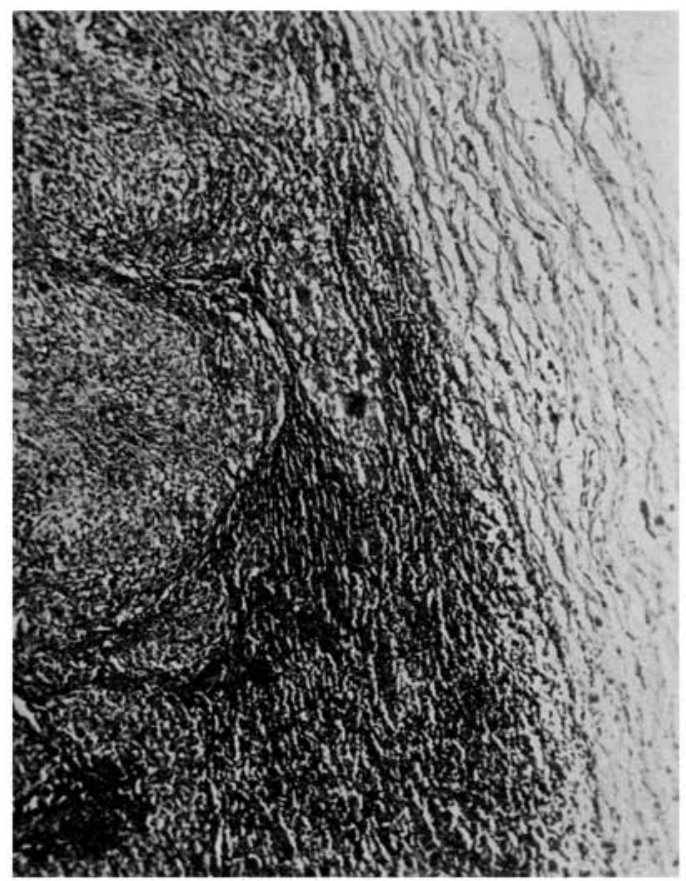

Fig. 4

G.L.S.C. 201/63-Lymph node in Leprosy. H \& E $\times 80$. Illustrates lymph node showing follicular hyperplasia with pale epithelioid cells thickening of capsule with A.F.B. $5 \%$ positive.

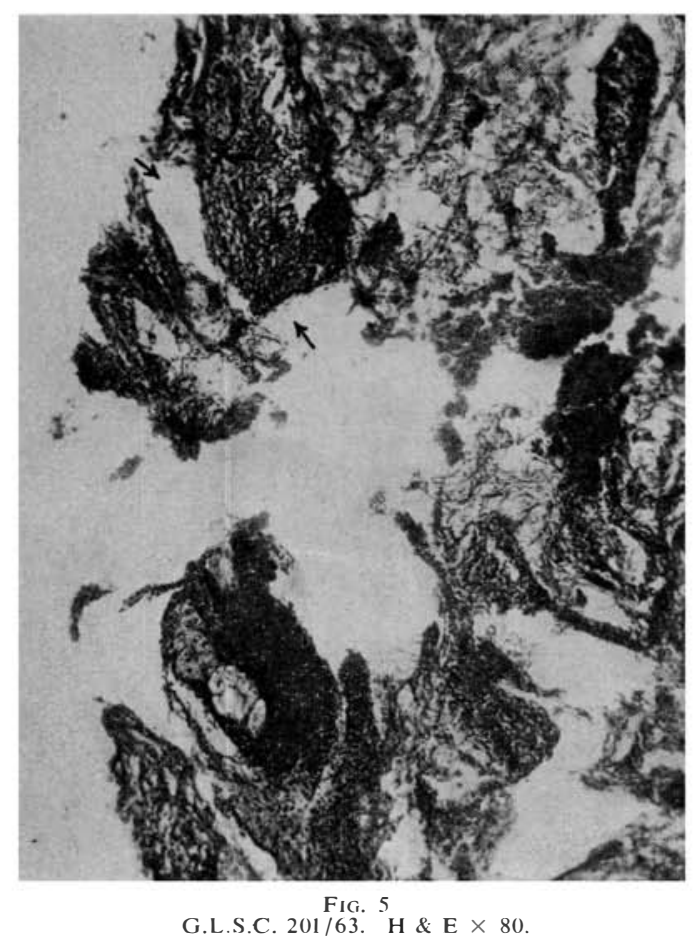

Skin in leprosy-shows collections of histiocytes at one end. deferens shows evidence of infiltration, with few chronic inflammatory cells-A.F.B. positive. TestisFibrosis, thickening of Basement membraneA.F.B. positive. Hydrocele fluid-nil particularBone marrow autolysed.

Note: Though the testis and adnexa with other biopsy specimens were sent the pathologists overlooked the histopathological study of the epididymis.

Patient 3-G.L.S.C. No. 105/59. V.N.B. Age 38 years. Indian Christian, educated, Government employee, married, 2 children. History of leprosy 25 years. History of lepra reaction 15 years.

Patient first examined by Dr. Cochrane at Vellore during early 1948 - has been under regular treatment since then. His first attack of epididymo-orchitis was during (October, 1963, and the present attack in June, 1967-the duration of attacks being 15 and 12 days respectively. On both occasions the patient was under the author's observation and treatment. He exhibits marked gynaecomastia of the right breast and has been impotent and sterile for the past 8 years. The patient did not consent to testicle biopsy.

Patient 4-G.I.S.C. No. 280/64. S. S. Sahib Age 35 years. Muslim, illiterate, sharescropper, married, 5 children. History of leprosy 15 years. History of lepra reaction 7 years. Semblance of libiclo present. Apart from his acute epididymo-orchitis the patient had marked cervical lymphadenopathy and lepromatous infiltration with development of an extensive patch over the right forearm in a skin area previously scalded in early childhood. Both the nipples and surrounding skin area were bilaterally infiltrated.

The patient was willing to have biopsy but refused orchidectomy. The following biopsy specimens were taken: (a) Testis with tunics; (b) Epididymis with tunics; (c) submandibular lymph gland; (d) lepromatous patch from scalded skin area.

Clinical photographs a, b, c, of the testis and the epididymis in situ were taken.

Report of histopathological studies by Dr. Sundarasiva Rao, M.D., Professor of Pathology, Government Ramnarayan Ruia Medical College, Tirupathi:Testis-Marcoscopic size $2^{\prime \prime} \times 1 \frac{1}{4}^{\prime \prime} \times 1 \frac{1}{4}$ ". Surfacesmooth and glistening. Colour-bluish white. Consistency - soft and vascular with no nodules feltepididymis enlarged and hard, particularly globus minor. A few delicate adhesions present between body of epididymis and testis proper.

Testis with tunies: Marked thickening of tunics with atrophy and wide separation of tubules. Hyalinized connective tissue with diffuse round cell infiltration and foam cell collections in the perivascular areas present between the tubules. The predominant change is a granulomatous infiltration of the interstitium with fibrosis and atrophy of seminiferous tubules. 'There is no actual increase in the interstitial cells.

A.F.B. were seen both intra- and extracellularly, in the interstitial tissue as well as inside the tubules. Vangieson showed moderate increase of connective tissue in tunica albugenia and peritubular areas with dilated blood vessels. 


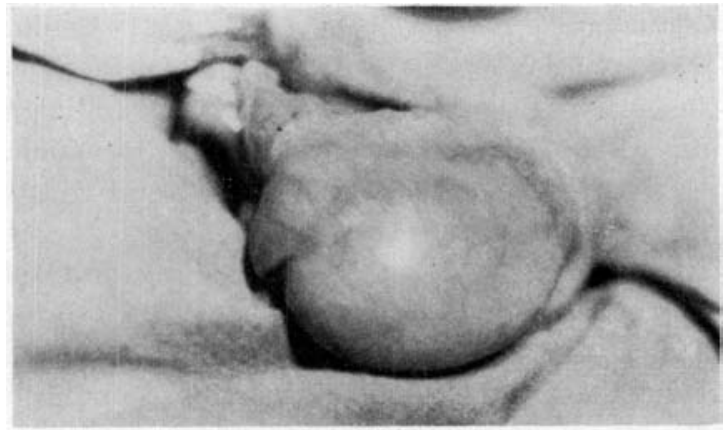

a

G.L.S.C. $280 / 64$.

Left testis and epididymis with tunica vaginalis in situ -both enlarged - surface smooth and glistening with a few blood vessels seen running transversely over testis.

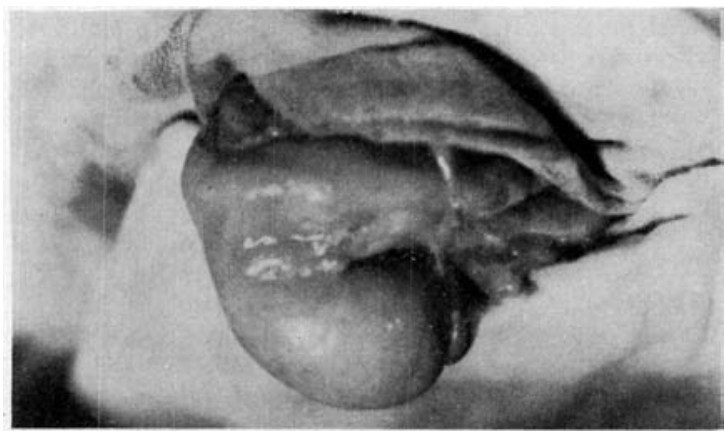

b

Parietal layer of tunica vaginalis incised and testis and epididymis exposed. Globus major and body moderately enlarged. Globus minor markedly enlarged and glistening. Delicate adhesions present between the testis and epididymis.

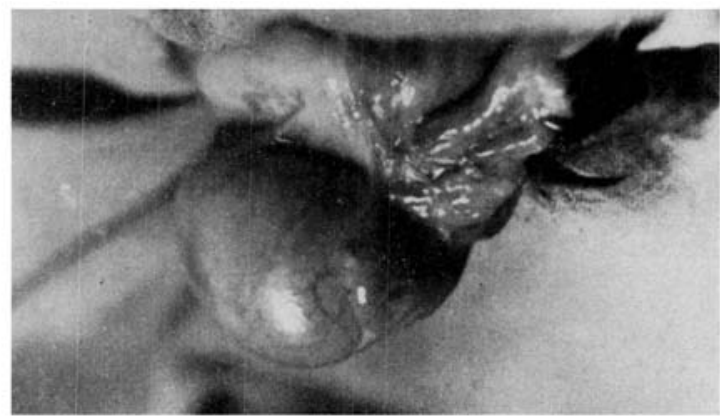

c

Another view of both these structures, showing relative enlargement and vascularity.
Epididymis with coverings: Showed commective tissue with dense diffuse chronic granulomatous infiltration around the vessels and obliterating them. The tubules look normal with moderate thickening of intertubular connective tissue. A.F.B. mostly extracellular were seen in the tunies only, sparing the epididymis proper. No actual chronic inflammatory cell infiltration and presence of A.F.B. could be made out in the epididymis proper. It looks as though the tunics only are involved sparing the epididymis. Submandibular lymph gland: Sections showed necrosis, epithelioid and giant cell reaction, with follicle formation. Few sections examined did not reveal A.F.B. organisms. However, considering the large number of foam cells, the lesion is only probably lepromatous.

Lepromatous patch from scalded skin area: There is atrophy of skin with flattening of papillary layer. Diffuse inflammatory round cell infiltration in perivascular, periglandular and perineural layers present with granulomatous changes.

All sections were examined after $\mathrm{H} \& \mathrm{~F}$, Vangieson and Acid Fast staining.

\section{DISCUSSION}

Testicular lesions are frequent in leprosy and their incidence in the different types have been admirably dealt with by Kobayashi (1920), Mitsuda and Ogawa (1937), A. L. Furniss (1956), Job and Macaden (1963), V. R. Khanolkar (1964) and H. W. Wade (1963).

Acute epididymo-orchitis in leprosy is nonsexual and non-venereal in origin and needs to be stressed. The author's series of 4 reports of patients confirms the occurrence of testicular lesions during repeated lepra reactions in advanced lepromatous leprosy. Ridley (1960) states in this connection 'that the reactions occur at the sites of small, pre-existing, lepra-cell granulomata'. It is as unfortunate as it is regrettable that the epididymis has not been studied at all save for the single autopsy study of the structure by A. L. Furniss (1956). Some of the most important physiological functions of spermatozoa 'like motility, maturation and spermatotrophic action occur in the epididymis which acts as a store house for them', Sampson and Wright (1965).

During repeated lepra reactions there is a flare-up with bacteriemia and widespread bloodborne dissemination of 'bacterial showers', and the testes become hypersensitised and receptive for the lodgement of $M$. leprae. The epididymis too participates in such a pathological process. 
These phenomena, though rare, do occur and are observable clinically and should be designated as epididymo-orchitis, instead of being termed as mere lepromatous orchitis. Such involvement would appear to be concurrent and simultaneous. It is suggested that future studies of the testis in leprosy should include the study of the epididymis as well irrespective of types. Further, such studies ought to be mandatory especially during reactive phases 'as the search of periodical literature of the past 30 years has been unrewarding and the occurrence of such lesions is not well documented in the literature'. H. W. Wade (1963).

\section{SUMMARY}

Four patients with acute epididymo-orchitis in advanced lepromatous leprosy in reaction were clinically studied by the author and are presented.

\section{ACKNOWLEDGEMENTS}

I am deeply indebted to the 2 patients for their cheerful, intelligent and willing cooperation and consent to parting with their testes. I would particularly like to thank Dr. I). J. Reddy, M.D., Director, Upgraded Institute of Pathology, Drs. Sundarasiva Rao, M.D., and C. Rajaram Mohana Reddy, M.D., Professors of Pathology, and Dr. K. Vasantha Rao, M.s., Assistant Professor of Surgery, Kurnool Medical College, for their active collaboration, help and advice.

I further wish to acknowledge my deep gratitude to the staff members of the Government Leprosy Subsidiary Centre, Kurnool, particularly Sri M. Danaiah, B.A., Senior Medico-Social Worker, without whose dedication this original work would have been well nigh impossible. The same applies to Sri L. Ramaiah, B.A., for his patient revision of several drafts before finally typing this article.

In conclusion, I wish to tender my grateful thanks to Dr. I. Bhoosan Rao, M.D., Director of Medical and Health Services, Andhra Pradesh, Hyderabad, for his kind permission to publish this article.

\section{REFERENCES}

1. CUnningham, D. J. (1962). Testis and Epididymis -Cunningham's Manual of Practical Anatomy, pp. $172-179$.

2. DAVEY, T. F. et al. (1964). Endocrines in Leprosy. Leprosy in Theory and Practice, XI, pp. 190-192.

3. FURniss, A. L. (1956). Testis in Leprosy. Ind. .J. Med. Sci., X, 7, 506-509.

4. Јов, с. K. et al. (1963). Leprous Orchitis in Reactional Borderline Patients. Int. .J. Lepr., 31, 273.

5. KHANOLKar, v. R. (1964). Pathology in Leprosy. Leprosy in Theory and Practice, 8, pp. 131-132.

6. ковауASHi, w. (1924). Detection of Lepra Bacillus in Testicular Tissues. Arch. Jermat., 2 (1964), Summary in .Jap. Med. World, 4, 269-270) (1924).

7. LONG, E. R. (1925). Assay on the basis of Spermatocyte Reaction. J. Infect. Dis., 37, 368-384.

8. mitsuda, k. et al. (1937). Study of 150 Autopsies on Leprosy Patients. Int. J. Lepr., 5, 53-60.

9. MUIR, E. (1962). Lepra Reaction and the G.A.S. Lep. Rev., 33, 240.

10. RIDLEY, D. S. (1960). A Bacteriological Study of Erythema Nodosum Leprosum. Int. .J. Lepr., 28, 254.

11. ROBInSON, R. H. O. B. (1950). Epididymis. British Surgical Practice, 183-186.

12. SAMSON and WRIGHT (1965). The testis, seminal tract and related glands. Applied Physiology 508.

13. WADE, H. W. (1963). Lesions of testis. Editorial, Int. .J. Lepr., 31, 3, 363. 